\title{
Formation of Synergetic Effect of Human Resource Management of Business Organization
}

\author{
Bagautdinova N.G.a \\ Levitsky B.E. ${ }^{b}$ \\ Vorobyeva L.E.c1 \\ Pratchenko O.V. ${ }^{d}$ \\ ad Kazan Federal University, Kazan, 420008, Russia \\ b LLC "Gazprom dobycha Krasnodar", Krasnodar, 350051, Russia \\ c Volgograd institute of economics, sociology and law, Volgograd, 400011, Russia \\ 1Email address: followaida@gmail.com
}

\section{Doi:10.5901/mjss.2014.v5n12p15}

\begin{abstract}
The article presents the contents of synergetic effect of human resources management of business organization which can be seen in excess of the sum of results of work of all employees as human capital bearers above the results of work of individual employees with unique professional competencies together with knowledge, abilities and experience as the sources of competitive strengths of business organization. Predictions of development of business organization - taking into account the influence of possibility of formation of synergetic effect on different stages of human resources life cycle - are presented.
\end{abstract}

Keywords: Human resources, synergetic effect, business organization, postindustrial economy, methods of human resources management.

\section{Introduction}

Changes in contents of traditional quartette of manufacturing factors which in conditions of intellectualization of economical processes touch upon, first of all, human resources; they cause their transformation into human capital and present as the Attributive characteristic of postindustrial economic structure. It is embodied in formation of principally new structure of national wealth of the developed countries, $16 \%$ of which is formed now by means of physical capital, $20 \%$ by means of natural capital and $64 \%$ - by means of human capital [2]. In some countries (Germany, Japan) this indicator is $80 \%$. According to estimate of the specialists of the Institute of economics of Russian Academy of Sciences, at the beginning of the XXI century in the Russian Federation (RF) the indicator of the national wealth per capital is one of the highest $(\$ 400000)$, which is 4 times more than worldwide average value. At the same time the size of accumulated human capital is $\$ 30 \mathrm{bn}$., and this is much less than the similar figures of the leading world powers. Thus, in the Russian economics there are no preconditions for formation and effective use of complex of abilities for labor, knowledge and skills, professional competencies, status-role characteristics and motivation of individuals as the main source of added value growth, and this prevents implementation of the stable socially oriented growth model.

\section{Methodology}

Corporate business capital which provides income generation by some employees, the enterprise and the state and which conditions synergetic effect of joint activities, becomes the key element of resource potential of contemporary business structure. Human capital presents complex of economic relations with participation of owners, employees, stake holders, state concerning realization of accumulate scope of knowledge, abilities and skills with the aim of achievement and re-distribution of economical and (or) social result. Use of human capital conception for the analysis of business activities allows to form complex approach concerning human resources management in long-term period; it makes 
individual and collective contribution in achievement desired strategic goals by business organization [4].

Contents of synergetic effect of functioning of business organization as the open system presents in the works of I. Adizes, I. Ansoff, G. Bishop, H. Campbell, D. Audretsch, M. Porter, L. Summers, F. Evans, etc.

Formation of postindustrial economic structure led to great changes in contents of manufacturing factors, which led to qualitative transformation of human resources, the creative part of which transformed into human capital as specific assets, as the complex of professional competencies, skills and abilities of individual, business organization, state, realization of which - under certain conditions - can provide additional income provision by the bearer and which is the source of positive externalities which can be seen in positive dynamics of economic and social indicators of condition of microeconomic and macroeconomic systems. Human capital of business organization - together with corporate and client capital - is a part of its intellectual capital. In its turn, human resources of business organization are interpreted as realized and realizable capital, as the object of measures of control action, structure of which is determined by contents of business strategy and aimed at transformation of accumulated by individuals professional skills and competencies as absolute and relative strengths of enterprise into stable competitive strengths [7;11].

Realization of human capital on the level of business entity brings to formation of different combinations of new knowledge connected with human and material resources, and it conditions formation of key competencies of business structure. In this case human resources are realized as the element of social organization in the unity of three main components - ability for intellectual-creative activities, social relations, in total composing social capital, unity of knowledge, abilities, skills and professional competencies.

In conditions of industrial economic structure labor as the unity of standard assets was the production factor. In conditions of postindustrial society characterized by processes of information system development and intellectualization of economic relations, importance of specific assets constantly formed during all life cycle of human capital rose. At the same time realization of potential of human resources as specific assets presupposes necessity to form effective business strategy aimed at realization of synergetic effect of management of them. Effect of synergy appears only in case of specific human capital, bearers of which have responsibilities for formation of competitive strengths of business structure and realize professional competencies using effective organizational communication. Effect of synergy completes the complementarity effect which is typical of industrial epoch and which consists of full use of resources available. Synergetic effect is seen in excess of the sum of results of human resources functioning above the results of individual functioning of some employees as bearers of individual human capital $[3 ; 5]$.

It cannot be interpreted as the synonym of positive effect of human capital realization, as far as it can take the positive, as well as the negative value, and this is embodied in dynamics of indicators of business structure functioning. Besides, participants of contracts' network who are the part of the company - owners, employees - act as recipients of synergetic effect. Formation of self-learning business organization with high level of reaction for changes of factors of environment, which generate innovations thanks to constant investment into human capital of employees, their personal and professional development, presents positive synergetic effect of human resources management. Synergetic effect is indirectly presented in profit as the result of competitive growth of business structure, its market share gains and effective management decision making. Aggravation of agent contradictions and increase of its subject matter at the expense of stake holders presents the form of negative synergetic effect of human resources management.

\section{Results}

Analysis of dynamics of synergetic effect in reference to life cycle of business structure indicates that on the nascent stage its level is maximum. It is caused by low costs of communication and coordination of activities, strong dependence of results of project realization from contents of human potential of the leader who can be characterized as an innovator, by domination of informal contracts. On the growth stage the level of synergetic effect is the highest which is caused by informal character of organizational communication and control, formation of the system of adaptation for foreign and domestic labor market (individual career planning, training and advanced training of personnel) [10].

Increase of hierarchy levels and specific weight of administrative management methods stimulate process of interaction and mutual exchange of professional competencies and knowledge, professional growth and staff turnover which increases variability of management decisions made in the frames of realization of business strategy. On the stage of maturity there is formalization of management by standardization of processes, rules and procedures, which levels down the participation of some employees and their groups in development and making of managerial decisions, practice of delegation of powers to subordinates is limited, effectiveness of organizational communication is blunted because of breaking of some bonds (horizontal, vertical or diagonal). On the stage of decline positive synergetic effect is neutralized or take on a negative value which is caused by escalation of conflicts and increase of transactional expenses of 
realization of communication.

The research showed that synergetic effect of human resources management (positive or negative) exists on all stages of the life cycle of business organization. Accumulation of human capital of organization is the necessary condition of formation and realization of positive synergetic effect which is provided by constant training and advanced training of staff, which, in its turn, leads to high reactivity of business organization, to changes of factors of ambient environment; by formation of informal intellectual groups inside the organization; contractions of agent relations which provides agent cost saving; increase of stock of shares which belong to company employees (if joint-stock company is the organizationallegal form of business) [6; 9].

Development of organizational capital of business is another necessary condition of formation and realization of positive synergetic effect, which creates conditions for exchange and collective accumulation of knowledge, cutting time for new knowledge acquisition. Organizational capital provides diffusion of private knowledge through internal network structures using information and communication technologies, provides their formalization and structuring, distribution of elements of corporate culture, increase of human resources loyalty level. Low efficiency of realization of organizational capital can become the reason of violation of rights of intellectual property which becomes the reason of negative synergetic effect. Formation of client capital (capital of relations), i.e. effective system of communications with stake holders (loyal customers, suppliers and partners), is the third condition of realization of positive synergetic effect; this is reflected in business reputation of business organization. Realization of communicative interactions provides increase of reactivity level of business enterprise, levels down economic risks.

On the initial stages of development of business structure diagnostics of potential of formation of positive synergetic effect is necessary to be realized on the basis of indexes of value structure (IVS) and correspondence of values of the businessman's team to the accepted by them values of the subject of business entity (VSBE). Index of value structure reflects the weighted average by the level of significance of its components proportion of individual, organizational, behavioral and client values of members of the businessman's team and business structure (in perception of the staff), and this index will be maximal (equal to 1) with full correspondence of structure of values in terms of the indicated types on the level of a member of the businessman's team and organization in whole; index will be minimal (equal to 0 ) with full absence of correspondence of values by structure.

As the analysis of practice of development of business structures on early stages of life cycle shows, positive synergetic effect can appear if this index exceeds the threshold limit value 0,7 . Index of correspondence of values of the businessman's team to the accepted by them values of the subject of business entity reflects the share of corresponding values of the businessman's team and business structure as holistic entity, which can also take on a value within the range from 0 to 1 , where 1 corresponds to the full match of values. 0,6 is the threshold limit value of this index, above which the formation of positive synergetic effect is possible. Thus, the bare chance, wherein in the process of development of business structure the positive synergetic effect is expected, is determined in the frames of multiplicative model of value indexes $h_{u c}$ (IVS) and $И_{c u k}$ (VSBE), and it's 0,42, which is the threshold limit value of probability for the other stages of life cycle of development of business structure as well. In the process of research it was found that $0,25 \mathrm{n}$ 0,2 are correspondingly the lowest threshold limit values for the indexes IVS and VSBE; underruns of these values allows to predict generation of negative synergetic effect and high probability of bankruptcy of business structure on early stages of life cycle.

Accelerated development of business structure on the basis of use of positive synergetic effect is greatly determined by condition of the complex of components of ambient environment of the business unit which include the level of protection of property rights, reaction of society to unintentional, conditioned by objective reasons bankruptcy of an enterprise, average level of quality/ personnel qualification on the labor market, availability of financial resources on condition of their high-risk use, condition of national measures, on all stages of its life cycle. At that on the initial stages condition of ambient environment determines development prospects of business organization (up to absence of realization of some business ideas) to a wider extent than on stages of stabilization and decline; at the same time in the frames of the set criteria turbulence of ambient environment determines the level of potential synergetic effect which is necessary for their overcoming, which can finally rise or fall in relation to the determined in the research threshold limit value 0,42 .

Characteristics of top-priority sources of synergetic effect of business structure in terms of the set factors are illustrated in Fig.1.The presented factors are considered in the frames of hierarchy, i.e. the factors of the first and second levels are prior in relation to the factors of the third-fifth levels, so the lag of the rise or fall of the threshold limit value of probability of synergetic effect will be determined by hierarchic level of significance of the corresponding factor. Consideration of the proposed sequence of formation of synergetic effect in business structure in terms of key characteristics of ambient environment is the necessary condition of effectiveness and efficiency of the proposed 
business strategy.

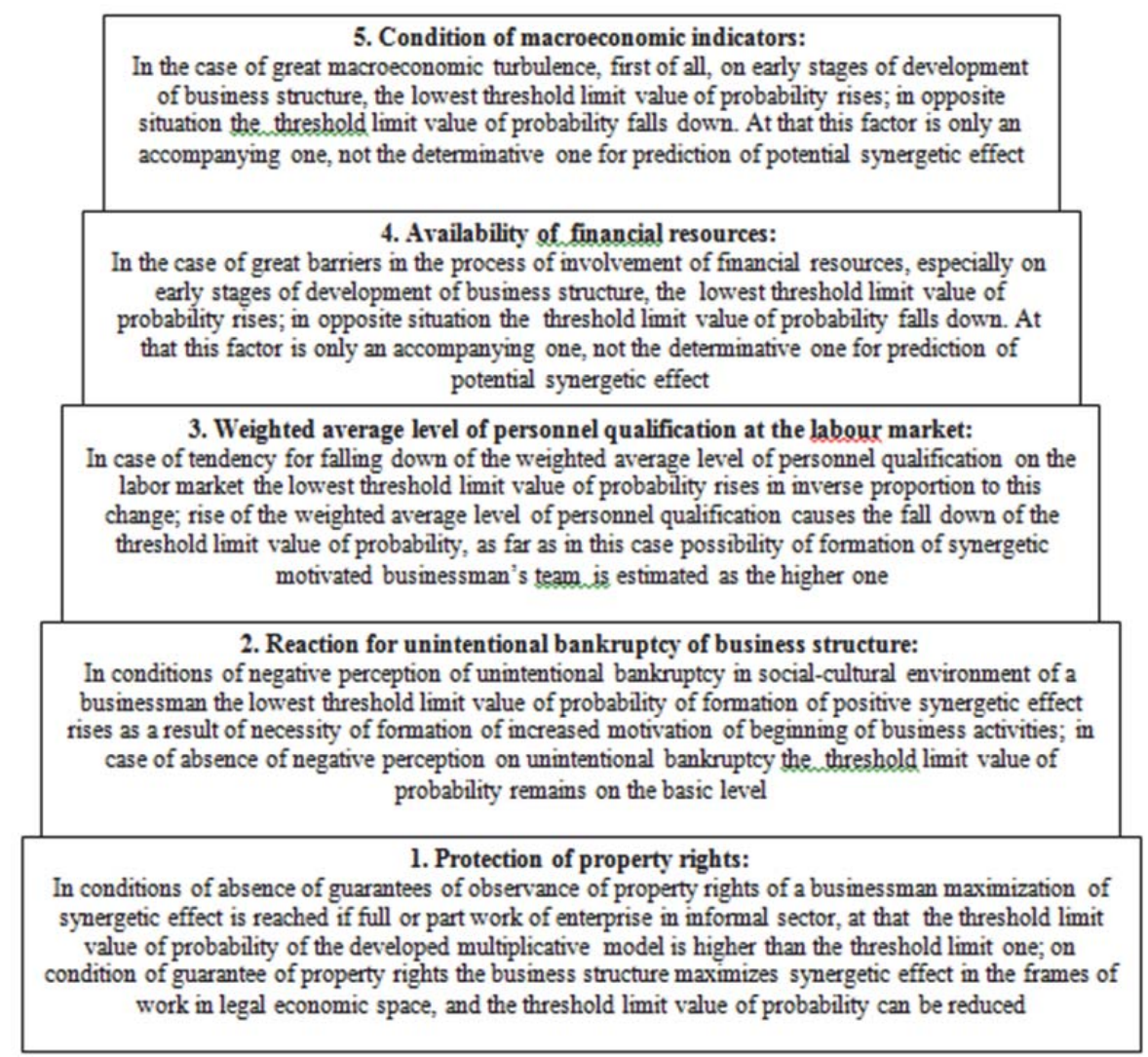

Fig. 1. Scheme of formation of synergetic effect in business structure in terms of key characteristics of ambient environment

Analysis of influence of synergetic effect on effectiveness of financial and operating activities of business structure showed that on initial stages of development of business the positive synergetic effect allows to provide significant efficiency increase; with the accumulation of synergetic effect the level of influence on efficiency decreases, i.e. influence of synergetic effect enhancement on resulting indicators of activities of business structure decreases. At the same time decrease of level of synergetics of interaction of the businessman's team which preconditions decrease of efficiency of use of business structure's resources, after some period of accumulation of synergetic effect, leads to sharp decrease of efficiency level. Thus, influence of positive synergetic effect on indicators of efficiency of business structure's activities (cost-effectiveness of activities of business entity on EBITDA) can be graphically presented in the form of hysteresis loop (Fig. 2). 


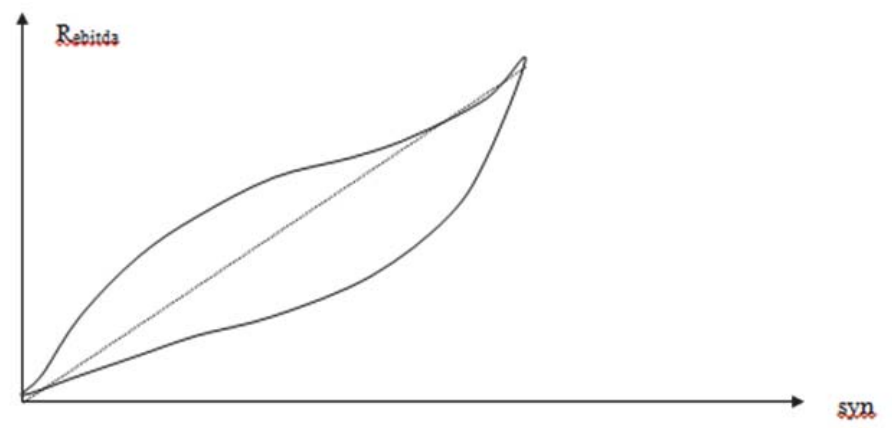

where Rebitda - cost-effectiveness of activities of business entity on EBITDA; syn - synergetic effect

Fig. 2. Hysteresis loop which characterizes influence of synergetic effect on efficiency of activities of business entity

Forecasting of development of business structure with account of influence of possibility of formation of synergetic effect on different stages of life cycle presupposes necessity of research of five key variants to provide its positive progressive dynamics:

1) scenario of stability, in the frames of which maintaining of current market position of business entity - with the absence of influence of synergetic effect - is provided;

2) scenario of growth, in the frames of which there is marketing development of business structure and/or efficiency of its financial and operating activities with the absence of influence of synergetic effect;

3) scenario of synergetic growth, in the frames of which accelerated expansion of marketing development of business structure with relation to scenario of growth and/or efficiency of its financial and operating activities caused by influence of synergetic effect, expressed by the highest threshold limit value of hysteresis loop (pic. 2), formalized as $1+f($ syn), and used as corrective predictive factor, is provided;

4) scenario of reduction, in the frames of which there is the contraction of market development of business structure and/or decrease of efficiency of its financial and operating activities with the absence of influence of synergetic effect;

5) scenario of synergetic reduction, in the frames of which there is the accelerated - in relation to scenario of reduction - the contraction of market development of business structure and/or reduction of its financial and operating activities, caused by influence of synergetic effect, expressed by the lowest threshold limit value of hysteresis loop (Fig. 2), formalized as 1 - $f($ syn), and used as corrective predictive factor in the predicative process of development of business structure's activities.

Realization of this approach will allow to provide accuracy and validity of forecasting activity of progressive dynamics of business structure which forms the platform of perspective evaluation of tendencies of stable growth of organization.

\section{References}

Becker G. Human Capital (2nd éd.). Chicago, 1975.

Fakhrutdinova, E., Safina, L., Kolesnikova, J., Fedor, Mikhailov. Quality formation of working life of the youth// World Applied Sciences Journal. Volume 27, Issue 13, 2013, Pages 87-91.

Glebova I.S., Rodnyansky D., Sadyrtdinov R., Khabibrakhmanova R. and Yasnitskaya Y. Evaluation of Corporate Social Responsibility of Russian Companies Based on Nonfinancial Reportingll Middle-East Journal of Scientific Research 13 (Socio-Economic Sciences and Humanities): 143-148, 2013.

Bertchel J. Personalmanagement. - Stuttgart: Schaffer - Poeschel, 2005.

Ulesov D.V., Murtazina G., Safiullin L.N. and Saipullaev U.A. Special Aspects of Development of Business in the Knowledge-Based Economy //World Applied Sciences Journal, 27(13), 2013, pp. 189-192.

Mayo A. Managing Carees: Strategies for Organizations. - London: IPM, 1991.

Kirshin I.A. Modeling the long-term trend of accumulation of knowledge. Life Science Journal 2014; 11(6s): 482 - 486.

Askhatova L.I., Fatkhiev A.M., Safiullin L.N. and Safiullina A.M. Competitive Strategies Formation in High Technology Enterprise // World 
Applied Sciences Journal, 27(13), 2013, pp. 20-23.

Pfeffer J. Competitive Advantage Through People. - Harvard Business School Press, Boston, MA, 1994.

Safiullin L.N., Shigabieva A.M., Mazitov V.M., Saipullaev U.A. Some methodological foundation of an innovation theory. Life Science Journal 2014; 11(6s): 388 - 391.

Gainova R.A., Shaidullin R.N., Safiullin L.N. and Maratkanova E.M. Infrastructural Component in Maintenance of Competitiveness of Region// World Applied Sciences Journal, 27(13), 2013, pp. 97-101.

Schultz, Theodore W. Investment in human capital: the role of education and of research. N.Y., 1971.

Validova A.F. Inflation targeting in developing countries: perspectives for Russia. Life Science Journal 2014; 11(6s): 494 - 498.

Hajrullina A.D., Romadanova O.A. Technique of measurement of value of the human capital as intangible asset of corporation. Life Science Journal 2014; 11(6s): 518 - 521.

Torrington D., Hell L. Personnel management: A new approach. - N.Y.; London, 1991.

Walker J.W. Human Resource Strategy. - McGraw-Hill, New York, 1992. 